\title{
Enhancing higher education students' employability and career management: A library service approach
}

\author{
Anne Davey \& Louise Kim Tucker \\ Bournemouth University, Poole, UK \\ 2010
}

\begin{abstract}
Purpose - The purpose of this paper is to discuss the Bournemouth University Library's approach to enhance students' employability and encourage their career management.
\end{abstract}

Design/methodology/approach - The library reviewed its trade publications collection and created a set of web pages to exploit these and newly discovered resources.

Findings - Piloting the project using a few subject areas helped to uncover any inefficiencies, discovered tools that could be used (e.g. Ulrichsweb and Intute) to gain the best information and enabled the creation of a set of guidelines to distribute across the team. There are four phases to this project: review, information gathering, decisions and promotion.

Practical implications - Sifting out good quality authoritative information takes time, although this process is aided by using tools such as Intute for example. It is important to keep the web pages up to date.

Originality/value - This paper discusses how a higher education library service can engage with students' career management.

Keywords: University libraries, Students, Career guidance, Career development, United Kingdom, Information services

Paper type Case study

\section{Introduction}

The impetus for students to acquire employability skills comes from a variety of sources including employers, government and educational institutions. Most employers are very specific about the skills required for a particular post, usually including a detailed person specification in the job details. Over the last 20 years in the UK there has been a whole range of government initiatives to encourage employability and the development of lifelong learning such as Enterprise in Education (1995). The Dearing Report (1997) stated that the development of such key skills should be the aim of every higher education (HE) institution. It concluded that the rapid change in the labour market and the unpredictability of the UK economy meant that "institutions will need to meet the aspirations of individuals to re-equip themselves for a succession of jobs over a working lifetime" (National Committee of Inquiry into Higher Education, 1997). In the light of these findings, HE institutions worked hard over the next decade to change their curricula to reflect the importance of employability skills for students and also to strengthen their links with local employers. 
More recently, an article published in Studies in Higher Education stated that "Employability issues are at the very core of contemporary HE in the UK" (Cranmer, 2006). "The graduate labour market is not a level playing field, and these graduates obviously do need to develop and effectively present the kinds of personal skills and qualities demanded by employers if they are to stand a chance" (Moreau and Leatherwood, 2006). For example, it has become very apparent over the last few years that "information literacy skills are too important to students' future success to be ignored" (Zalaquett and Osborne, 2007). The current economic downturn and subsequent recession has put pressures on the job market and in turn this has increased the pressure on universities to produce employable graduates. David Rae (2008) commented "given that the UK may be about to experience for the first time a period of economic downturn during the era of mass participation in higher education ... It is unclear what implications these factors may have for higher education". It is now extremely important that a graduate leaves HE with a deeper knowledge of the labour market. Given that an increasing number of people are obtaining degrees, the ability to stand out from the crowd has become far more desirable.

\section{The Bournemouth University (BU) context}

$\mathrm{BU}$ has a long tradition of teaching courses designed to produce employable graduates with a wide range of transferable skills. The 2007/2008 Destination of Leavers from Higher Education report shows that of 1,825 BU respondents 91 per cent successfully moved on to employment or further study (HESA, 2009). The BU Corporate Plan states that:

High quality and challenging education geared to employability will be sustained by the services and support [e.g. virtual learning environments (VLE)] that will allow each student to achieve their potential (Curran, 2005).

In 2008 Brian Astin, Pro-Vice Chancellor for Education, issued an internal paper which reinforced the University's commitment to producing "self-motivated lifelong learners". In this paper, which was made available to all BU staff and students, he outlined the changes to the curriculum and the teaching delivery methods which would produce autonomous self-directed learners rather than passive consumers. One important theme of this document was the need for students to develop a range of skills such as being able to research effectively and work in groups. It acknowledged that "relatively few of these attributes are developed directly in the lecture theatre as they require higher order skills. Indeed, employers of our graduates expect their newly appointed staff to be proactive and able to make an immediate and effective impact". Brian Astin's paper became the catalyst for our project. Not only did it give us the opportunity to tie our activities more closely into the BU corporate and Brian Astin's aspirations, but it also allowed us to integrate the Library provision more deeply into the curriculum.

The majority of BU students are offered an optional work placement year where they can gain employee experience in the sector they are studying. In this context, a principle that underpinned our project was to give career management skills greater attention, thus enabling an opportunity for BU students to enhance their employability. 
"Regardless of how services are provided graduate student career issues must be placed in the context of other developmental and life issues that students face" (Lehker and Furlong, 2006). In addition to the work placement opportunities, the University's Graduate Employment Service work with each school to provide students with career planning sessions tailored to their particular needs. The Library Professional Awareness Project allowed us to further enhance and support the work being done by the Graduate.

Employment Service: Students learn in a variety of ways and "we have to look at the whole teaching-learning environment provided for the students, including the various types of teaching, e-learning and other forms of support provided" (Entwistle, 2005). The aim of this project was to create an easily accessible resource that provides reliable sources of research, and information that allows students to gain "knowledge about the ways in which organisations work, what their objectives are and how people in those organisations do their jobs"' (Mason et al., 2009).

\section{The pilot project}

BU Library subscribes to a wide range of trade and professional publications. Over the last five years there has been a steady move from print subscriptions to electronic format. In addition to an increase in published material, many publishers are making extra materials available via their web pages. Some of this content is only available to subscribers and registered users, but much of it is accessible free of charge. The challenge was to exploit the existing subscriptions and also to give students and staff easy access to this extra material. The aim was to create a central web page, arranged by subject, with links to relevant journals, trade magazines and associations. This would supply materials for students to develop an awareness of their chosen subject area or profession.

BU Library has a well-established team of subject librarians and subject support librarians with very strong links to academic schools within the University. The timeliness of this project with regard to the BU Corporate Plan, and the rapidly changing technology placed the subject librarians in an ideal position to develop the web pages. It was decided that a small pilot project would be carried out in one of the schools, before launching it to the whole University community. The School of Design, Computing and Engineering (DEC) was chosen as it has a changing curriculum that includes large cohorts and new professional opportunities for graduates in psychology. The subject librarian and subject support librarian were tasked with carrying out the pilot and producing some written guidelines for the other teams.

\section{Identifying the process}

The process involved reviewing existing subscriptions for professional publications (magazines and journals which target a specific career/trade/sector) and focusing on exploiting online content including material that is free to access.

Our objectives were as follows:

- To analyse current journal subscriptions and assess whether any titles could be switched from print to electronic access only;

- To choose which tools to use to gather information about professional publications; 
- To identify free content outside existing subscriptions; and

- To create guidelines for subject team colleagues to use when the project was rolled out across all schools.

The subject support librarian was the information gatherer, using a range of tools to collect and present the data to the subject librarian who made an informed decision (involving their knowledge of courses and the needs of our students) about what content would be included on the professional awareness web pages.

\section{Identifying the topics}

The project began as a pilot using the subject area psychology, a relatively new course provided by BU.

Once the psychology area was completed other subject areas within the School of DEC were tackled. Careful consideration was given to the subject areas and how to describe them so that they would be recognisable and relevant to BU students. Sources used to locate professional associations included:

- Colleagues (e.g. academics) recommendations.

- Intute, www.intute.ac.uk.

- Trade Association Forum, www.taforum.org

Sources to locate journals and magazines included:

- Business Source Complete.

- BRAD.

- TechXtra, http://techxtra.tradepub.com/

A key resource was the online periodicals directory Ulrich's Periodicals Directory [1] (Figure 1). Initially, the "lists" function was used to gather and share records of trade publications to be checked.

Ulrichweb's "advanced search" proved invaluable for conducting a focused and quick search of professional publications. The screen shot image in Figure 2 shows an example of how to construct the search.

\section{Challenges encountered during the pilot}

A consequence of using the Ulrich's lists feature (Figure 2) was it generated very long lists, which proved challenging because the information took a lot of time to sift through. A spreadsheet was created to enable the subject librarian to filter the information from the lists more effectively. The spreadsheet included the following column headings:

- Source.

- Professional press/Association title.

- URL.

- Description (detail that will be added below the live link on Professional Awareness web pages).

- Online coverage.

- ISSN (if applicable).

- Do we have print access?

- Do we have e-access via our A-Z by title e-journals web page? 


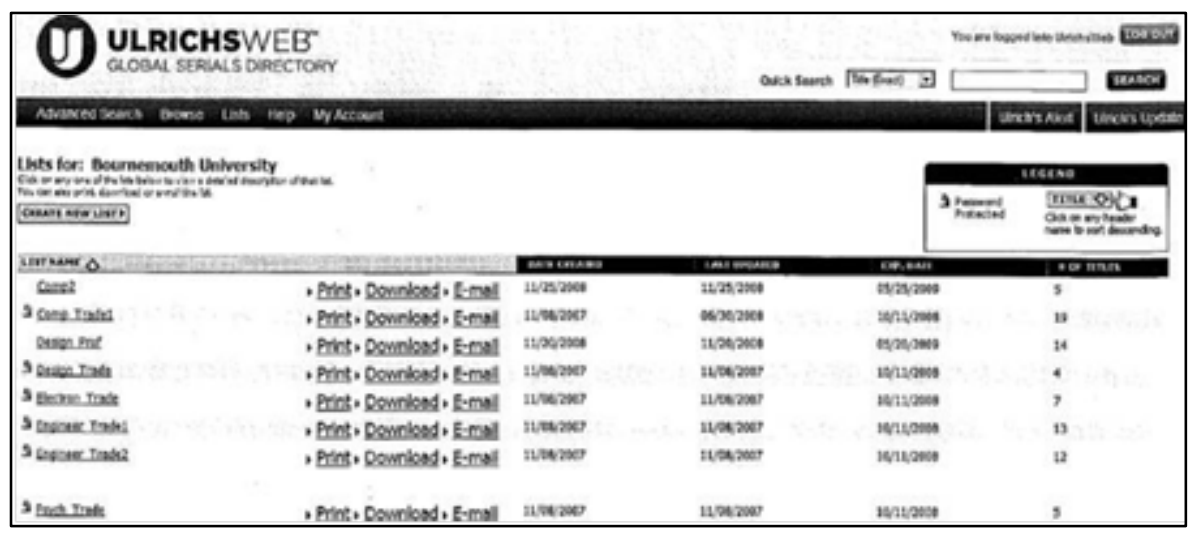

Figure 1. Screenshot of Ulrichsweb's lists page

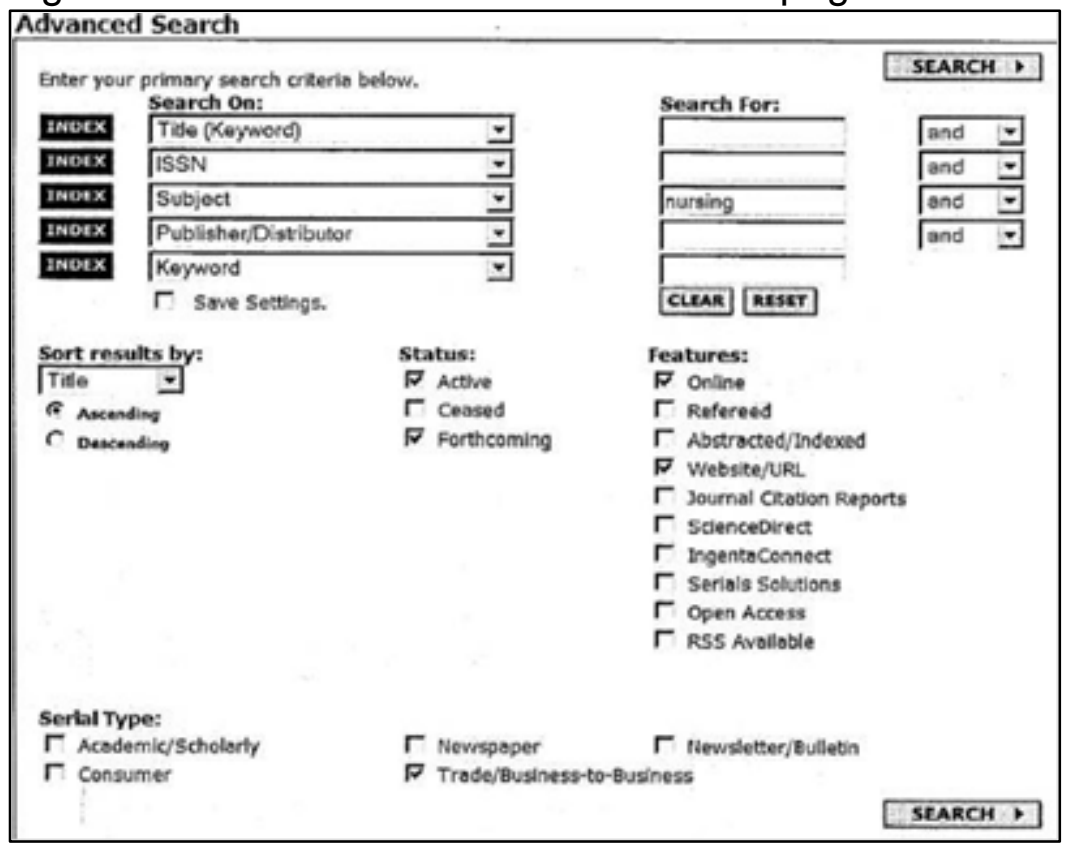

Figure 2. Screenshot of Ulrichsweb's advanced search

\section{Collaboration}

It is important to note that this was a collaborative effort between the subject teams and academics within the school. The question was at which stage of the process we should involve academic colleagues. The factors taken into consideration were:

- The relationship that the subject librarians have with academics within the schools.

- The value of involving academics at an early stage so that the project would benefit from their input to add resources that they are already aware of.

- Awareness that involving academics in the decision process might trigger requests for access to subscription resources and therefore the need for negotiation if funds were not available.

\section{Co-ordination}

Once the DEC subject team had got to grips with the pilot phase, the project was rolled out across the three other subject teams. The DEC subject support librarian took on the role of co-ordinator and oversaw the process of taking the project beyond the pilot stage, devolved tasks and kept track of what stage colleagues were at. 
The DEC subject team recommended that the subject support librarians be the information gatherers, referring to our package of tools, tips and guidelines to collect and present the data. Then our subject librarians were the data analysers making informed decisions about what content would be included on the professional awareness web pages. Their decisions were based on their knowledge of courses and the needs of our students, while calling on the advice of academics where appropriate.

This turned out to be the most practical and workable approach; since the subject support librarians could invest more time in gathering data, we had learned from the pilot that this stage consumes the most time. We found having a team member in a co-ordinating role helped to efficiently move the project forward and ensure each subject team contributed towards making our web pages live online for our spring 2009 deadline.

Developing the project beyond the pilot stage

A recommendation from the pilot highlighted to colleagues the importance of entering discussions with relevant academic staff ideally before starting the review process. This enabled subject teams to establish which resources should already be in place and refine their search strategies for new materials. In practice, it was found that subject team colleagues chose to consult academic colleagues at different stages throughout the process due to varied networks and relationships with schools.

The subject teams were encouraged to produce web pages for areas relevant to their schools. The project co-ordinator created a package of tools, tips and guidance was created that they could refer to within a shared e-folder. Along with the spreadsheet template described in section six, this package included a set of guidelines instructing colleagues how to approach the task. Presented in report and flowchart formats, they indicated the following key phases of the project:

\section{Review}

- Review existing trading publication collection and identify titles already in stock.

- Information gathering. Identify any gaps in the collection and which subject areas to focus on (includes potential liaison with academics).

- Decisions. Liaise with acquisitions team to arrange subscriptions to any new titles identified; and decide which titles can be migrated from print to electronic.

- Promotion. Select any key titles that can be accessed via the professional awareness web pages; and identify where professional awareness web pages will be promoted.

\section{Challenges encountered during the project roll out}

The project work was extended to subject teams in November 2008, when a web page structure was in place. The first web page launched was for psychology, a new course at BU encouraging graduates to be engaged with professional associations during their time at University. 
The project co-ordinator needed to liaise with our Library Access Technologist who is responsible for creating Library web pages. This colleague had restrictions on their time, which had an impact on the timing of the launch. A consequence of this, plus unexpected internal pressures, meant that a bulk of the work towards producing the rest of our web pages occurred between November 2008 and March 2009. The first term of an academic calendar is particularly busy, on reflection a better time for the roll out would have been during the student's summer vacation period. However, working within the imposed time restraints, the project co-ordinator encouraged subject teams to take advantage of the student's Christmas vacation period when there are fewer demands on their time.

In March 2009 it was decided that due to the rapid changes in information technology details of any web 2.0 technologies that the professional association web sites are using (specifically RSS feeds, blog and wikis) would be added to the professional awareness web pages. As a result, tweaking and adjustments to the web pages continued between March and May 2009.

Along with the challenges of time and deadline, the workload was shared and managed by each subject team (a total of 11 staff split into four teams, each led by a subject librarian, with subject support librarians working across teams). Colleagues were contributing information covering many different subject areas, so it was helpful to have a co-ordinator in place to keep track of who was doing what and when. The co-ordinator acted as a filter between the teams, the library access technologist (web manager) and the senior members of the service, which proved successful because it provided one central point of communication. It involved overseeing the work outputs of each Subject Team, liaising with and instructing our web manager, and reporting to senior colleagues (see Figure 3).

\section{Promoting the project}

The final tasks were to design the new web pages, attract users to them and make the value of the information clear. As the words "professional journal" can be very ambiguous and it was felt that "trade journal" could be misleading, the area was called professional awareness. This title and the wording of the home page were designed to echo the comments made about employability by Brian Astin in his paper. It was apparent that while promoting these career-focused resources, there was an important opportunity to also point users in the direction of BU's Graduate Employment Service. Therefore, a link to this service was added on the professional awareness home page.

The project was promoted via the following sources:

- Library subject guides.

- Library web pages.

- The University's VLE (myBU).

- Digital signage in the Library.

- Library A-Z by title e-journals web page.

Each source is explained in more detail below. 
The new resource was added to the DEC subject guides, a series which is reviewed and updated each summer. It included a standard section providing a few select links to professional associations as follows:

\section{Professional Awareness:}

You are encouraged at BU to develop appropriate academic and professional knowledge and skills to enhance your employability. The professional awareness web pages (hyperlinks to www.bournemouth.ac.uk/library/resources/ prof_aware.html) provide links to professional associations and associated publications which will support your learning.

Many of the associations and publications include job vacancies, blogs, alerting services (via RSS feeds and e-newsletters, for example) and details of other organisations.

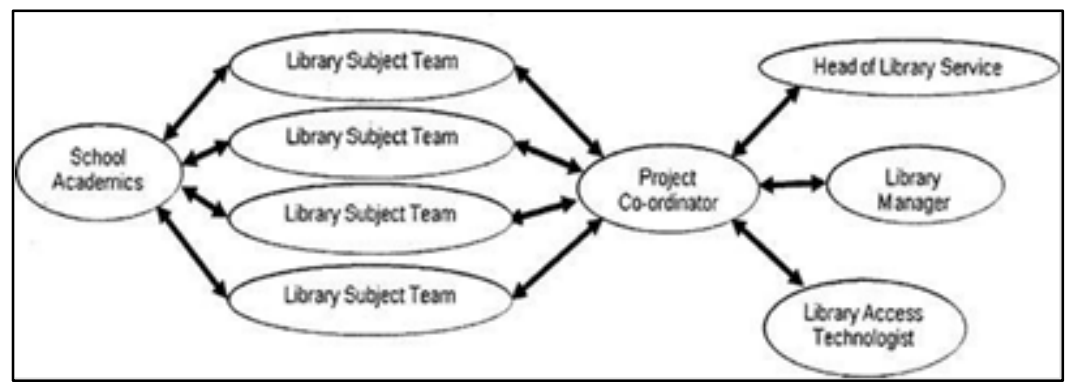

Figure 3. Project channels of communication

\section{Library web pages}

It was necessary to communicate to users that the professional awareness web pages (www.bournemouth.ac.uk/library/resources/prof_aware.html) were being added to as each subject area was completed, so the following statement was included on the web page: "This area is currently under development and more subject areas will be added over the coming months". The web page was refined and enhanced as the service grew.

\section{VLE (blackboard)}

The University VLE, myBU, has a tab devoted to Library services which acts as a portal to access our resources. The professional awareness pages were highlighted in the section that includes the subject team's contact details (as shown in Figure 4). The subject teams have a well-established system of one-to-one and small group appointments, along with information literacy skills sessions, providing an opportunity to promote the professional awareness resources face to face. In response to email queries from individual students, these resources are promoted whenever appropriate.

\section{Project outcomes and future developments}

The work was carried out during the normal academic year, with its peaks and troughs of activity. It was decided that the DEC Subject Team, who ran the pilot, would continue to manage the project. 


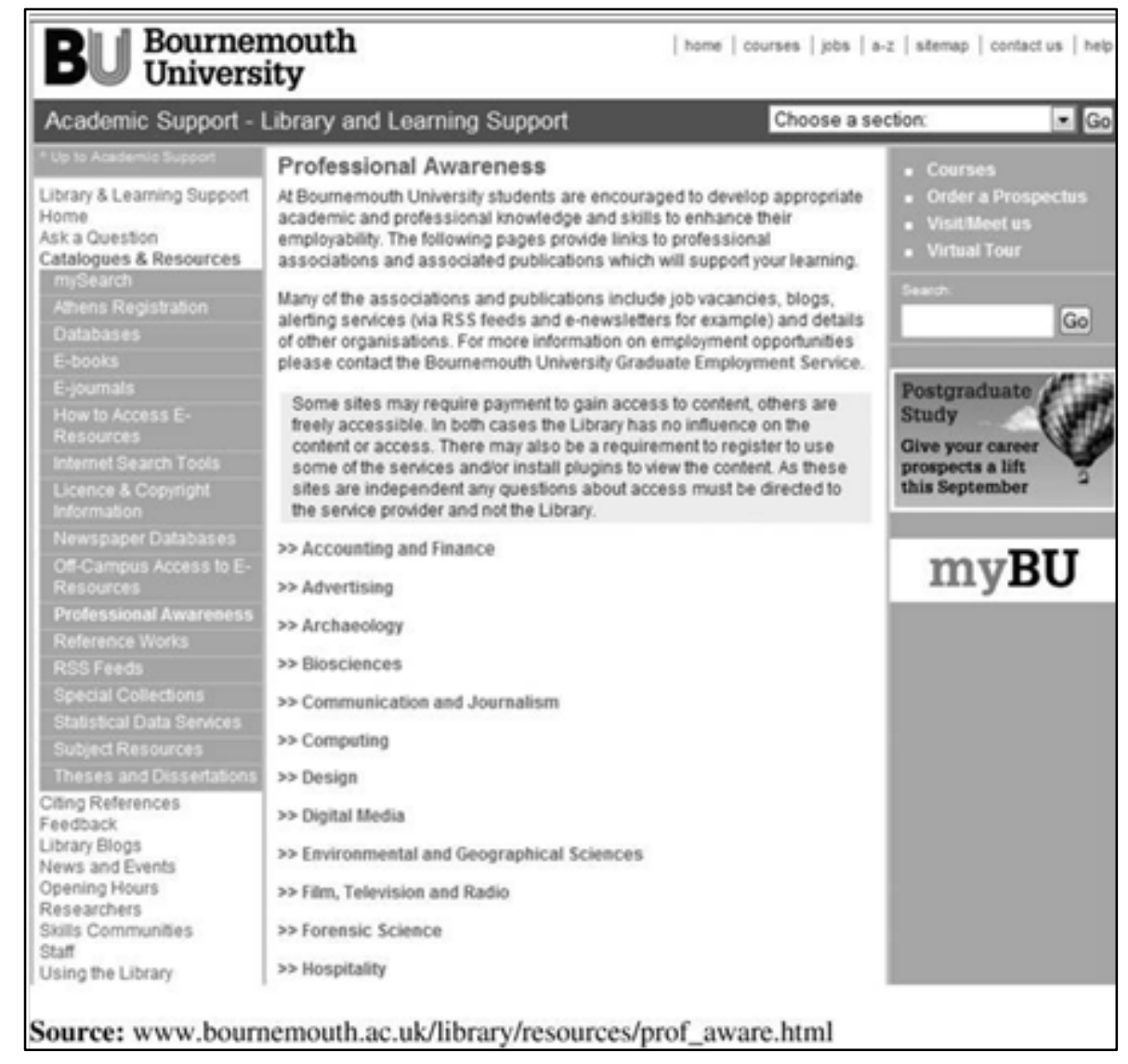

Figure 4. Wording currently used on the Library web page (November 2009)

They were tasked with co-ordinating the workflow of colleagues to ensure completion by an agreed deadline. The project began in July 2007 and the web pages were completed by May 2009.

Some subject areas were more easily defined than others and frequently overlapped across academic schools. Therefore, collaboration and negotiation had to take place to ensure that the process progressed smoothly. Creating web pages for such a wide range of subjects has provided a good opportunity for colleagues to work closely together. It also gave an opportunity to identify areas where colleagues could work more closely together in the future.

The subject teams needed to ensure that these web pages are not too overwhelming for users or an onerous task to keep up to date. As a result of this the responsibility of keeping the information up to date and checking hyperlinks remain live has been spread among the subject teams.

The approach taken to develop the professional awareness web pages could also be applied to reviewing standing orders. Historically, BU Library has subscribed to a large number of loose leaf print publications, mainly in the law subject area. Over the last five years there has been a steady move from print to electronic materials. This has resulted in a lot of electronic content which is possibly not being fully exploited by Library staff, academics or students. Therefore, developing this area along the lines of the Professional Awareness Project would seem to be the next logical step. 


\section{Conclusion}

This has been a very useful project for all involved. It has enabled BU Library to open up more electronic content for its users, thereby adding value to our award winning Library service [2]. In the wider context there will be other benefits to students. "There would appear to be economic benefits if HE providers begin to play a more active role in developing students' career management skills" (Bridgstock, 2009). It is also hoped that by creating this Professional Awareness area BU students will, in the words of Brian Astin, "...be active, informed and engaged participants in an academic community...not to be passive consumers".

However, on reflection, there are a number of things which could have been done differently. The timing of the project was less than ideal; the recommendation from the pilot project team is that the summer vacation would be the most appropriate time to create such a resource. This would not only allow the Subject Teams to spend more time sifting through the resources, but would also give an opportunity to plan the promotion of the resource more carefully. Throughout the whole process two things became apparent. First, the academics need to be involved from the early stages of the project. Second, the role of the co-ordinator is crucial, it enables the project to be rolled out uniformly, smoothly and efficiently.

\section{Note}

1. www.ulrichsweb.com/ulrichsweb/

2. 2009 winners of the Times Higher Education Leadership and Management Award for "Outstanding Library Team".

\section{References}

Bridgstock, R. (2009), "The graduate attributes we've overlooked: enhancing graduate employability through career management skills", Higher Education Research and Development, Vol. 28 No. 1, pp. 31-44.

Cranmer, S. (2006), "Enhancing graduate employability: best intentions and mixed outcomes", Studies in Higher Education, Vol. 31 No. 2, pp. 169-84.

Curran, P. (2005), "[Bournemouth University] Corporate Plan: a statement of strategic intent", available at:

www.bournemouth.ac.uk/about/introduction_to_bu/downloads/Corporate\% 20Plan\%20June\%2006.doc (accessed 5 November 2009).

Entwistle, N. (2005), "Enhancing teaching-learning environments in undergraduate courses in electronic engineering", International Journal of Electrical Engineering, Vol. 42 No. 1, pp. 1-7.

HESA (2009), "Performance indicators in higher education in the UK 2007/08", available at:

www.hesa.ac.uk/dox/performancelndicators/0708/e1_0708.xls (accessed 9 March 2010).

Lehker, T. and Furlong, J.S. (2006), "Career services for graduate and professional students", New Directions for Student services, Vol. 115, pp. 73-83.

Mason, G., Williams, G. and Cranmer, S. (2009), "Employability skills initiatives in higher education: what effects do they have on graduate labour market outcomes?", Education Economics, Vol. 12 No. 1, pp. 1-30.

Moreau, M.P. and Leatherwood, C. (2006), "Graduate's employment and the discourse of employability: a critical analysis", Journal of Education and Work, Vol. 19 No. 4, pp. 305-24. 
National Committee of Inquiry into Higher Education (1997), Higher Education in the Learning Society, HMSO, London.

Rae, D. (2008), "Riding out the storm: graduates, enterprise and careers in turbulent economic times", Education and Training, Vol. 50 Nos 8/9, pp. 748-63.

Zalaquett, C.P. and Osborne, D.S. (2007), "Fostering counseling students' career information literacy through a comprehensive career web site", Counselor Education \& Supervision, Vol. 46, pp. 162-71.

\section{Further reading}

Entwistle, N. (1988), Styles of Learning and Teaching: An Integrated Outline of Educational Psychology for Students, Teachers, and Lecturers, David Fulton, London.

Hind, D. and Moss, S. (2005), Employability Skills, Business Education Publishers, Sunderland. Mason, G., Williams, G., Cranmer, S. and Guile, D. (2003), "How much does higher education enhance the employability of graduates?", available at: www.hefce.ac.uk/pubs/rdreports/

2003/rd13_03/default.asp (accessed 5 November 2009).

Whiteley, T. (1995), "Enterprise in higher education - an overview from the department for education and employment", Education and Training, Vol. 37 No. 9, pp. 4-8. 